\title{
Homeostatic Strengthening of Inhibitory Synapses Is Mediated by the Accumulation of $\mathrm{GABA}_{\mathrm{A}}$ Receptors
}

\author{
Matthew D. Rannals ${ }^{1}$ and Jaideep Kapur ${ }^{2}$ \\ ${ }^{1}$ Neuroscience Graduate Program, University of Virginia, Charlottesville, Virginia 22908 and ${ }^{2}$ Department of Neurology, University of Virginia, Health \\ Sciences Center, Charlottesville, Virginia 22908
}

Mechanisms of homeostatic plasticity scale synaptic strength according to changes in overall activity to maintain stability in neuronal network function. This study investigated mechanisms of GABAergic homeostatic plasticity. Cultured neurons exposed to depolarizing conditions reacted with an increased firing rate (high activity, HA) that normalized to control levels after $48 \mathrm{~h}$ of treatment. HA-treated hippocampal neurons displayed an attenuated response to further changes in depolarization, and the firing rate in HA-treated neurons increased above normalized levels when inhibition was partially reduced back to the level of control neurons. The amplitude and frequency of mIPSCs in hippocampal neurons increased after $48 \mathrm{~h}$ of $\mathrm{HA}$, and increases in the size of GABA $\mathrm{A}$ receptor $\gamma 2$ subunit clusters and presynaptic GAD-65 puncta were observed. Investigation of the time course of inhibitory homeostasis suggested that accumulation of $\mathrm{GABA}_{\mathrm{A}}$ receptors preceded presynaptic increases in GAD- 65 puncta size. Interestingly, the size of GABA $\mathrm{A}_{\mathrm{A}}$ receptor $\gamma 2$ subunit clusters that colocalized with GAD- 65 were larger at $12 \mathrm{~h}$, coinciding in time with the increase found in mIPSC amplitude. The rate of internalization of $\mathrm{GABA}_{\mathrm{A}}$ receptors, a process involved in regulating the surface expression of inhibitory receptors, was slower in HA-treated neurons. These data also suggest that increased receptor expression was consolidated with presynaptic changes. HA induced an increase in postsynaptic $\mathrm{GABA}_{\mathrm{A}}$ receptors through a decrease in the rate of internalization, leading to larger synaptically localized receptor clusters that increased GABAergic synaptic strength and contributed to the homeostatic stabilization of neuronal firing rate.

\section{Introduction}

Homeostatic plasticity has been described as the precise tuning of neuronal excitability to maintain a neuron's target activity level (Marder and Goaillard, 2006). This theory predicts that synaptic strength will scale in the direction that counteracts any change in excitability. At the synapse, homeostatic plasticity has been observed as increases or decreases in synaptic strength following corresponding changes in neuronal network activity.

At excitatory synapses, activity blockade has been shown to result in an increase in quantal currents mediated by glutamatergic receptors (O’Brien et al., 1998; Turrigiano et al., 1998); while increases in activity through a blockade of inhibition results in decreases in excitatory quantal currents (Lissin et al., 1998; O’Brien et al., 1998; Turrigiano et al., 1998). Along with changes in these quantal amplitudes, activity-dependent changes in the expression of glutamatergic receptors have been observed, suggesting an important role for postsynaptic mechanisms (Rao and Craig, 1997; Lissin et al., 1998; O’Brien et al., 1998; Turrigiano et

\footnotetext{
Received Sept. 1, 2011; accepted 0ct. 10, 2011

Author contributions: M.D.R. and J.K. designed research; M.D.R. performed research; M.D.R. and J.K. analyzed data; M.D.R. and J.K. wrote the paper.

This work was supported by National Institutes of Health Grants R01 NS 040337, R01 NS 044370, and U01 NS 58204. We thank Howard Goodkin, Corinne Balint, Suchitra Joshi, and Karthik Rajasekaran for their careful reading of this manuscript and thoughtful comments, and Hui Wei Chen and Kendra Keith for the preparation of hippocampal cultures.

The authors declare no competing financial interests.

Correspondence should be addressed to Jaideep Kapur, Department of Neurology, Box 800394, University of Virginia, Health Sciences Center, Charlottesville, VA 22908. E-mail: jk8t@virginia.edu.

DOI:10.1523/JNEUROSCI.4476-11.2011

Copyright $\odot 2011$ the authors $\quad 0270-6474 / 11 / 3117701-12 \$ 15.00 / 0$
}

al., 1998). In addition to synaptic blockades used to control activity levels, postsynaptic depolarization with elevated $\mathrm{KCl}$ has been shown to decrease excitatory synaptic strength (Leslie et al., 2001).

Although studies of activity-dependent changes at excitatory synapses have furthered our understanding of homeostatic mechanisms, the effects of chronic activity changes at inhibitory synapses is not as clearly defined. Studies of homeostatic plasticity at inhibitory synapses have shown decreased synapse strength following chronic activity blockade (Hartman et al., 2006; Swanwick et al., 2006a). Some of this work suggests presynaptic mechanisms regulate homeostatic plasticity during $9 \mathrm{~d}$ treatments of activity blockade (Hartman et al., 2006), while shorter chronic activity blockade for $2 \mathrm{~d}$ has resulted in mixed evidence for presynaptic changes (Swanwick et al., 2006a). More recent work has found changes in inhibitory synaptic strength after $4 \mathrm{~h}$ of increased activity, which corresponds to descriptions of activitydependent changes seen at glutamatergic synapses within $4 \mathrm{~h}$ (Ibata et al., 2008; Peng et al., 2010). Remaining unresolved, however, is how the timing of postsynaptic and presynaptic mechanisms correspond to altered inhibitory synapse strength. In addition, the homeostatic scaling of postsynaptic $\mathrm{GABA}_{\mathrm{A}}$ receptor expression through the modulation of receptor turnover at these changing synapses has yet to be described.

In the current study, hippocampal neurons demonstrated a homeostatic regulation of firing rate when challenged by chronic depolarization. Prolonged depolarization increased inhibitory postsynaptic $\mathrm{GABA}_{\mathrm{A}}$ receptor expression, followed by an increase in the presynaptic marker GAD-65. The increase in the area of 
colocalization of both markers corresponds in time to the observed increase in synaptic strength measured by mIPSC amplitude. The rate of internalization of $\mathrm{GABA}_{\mathrm{A}}$ receptors was also slower in these treated cultures. Together the data suggest that chronic depolarization leads to an initial increase in inhibitory postsynaptic receptors at the neuronal membrane due to a reduction in the rate of internalization; that inhibitory synaptic strength does not scale homeostatically until presynaptic changes are also consolidated at synapses; and that scaling of synaptic strength contributes to the homeostatic stabilization of firing rate in hippocampal neurons.

\section{Materials and Methods}

Hippocampal cell culture. Neuronal hippocampal/glial cocultures were prepared from $18 \mathrm{~d}$ embryonic rats following methods described previously (Goslin et al., 1998) and modified (Mangan et al., 2005). Treatment of animals followed a protocol approved by the University of Virginia Health Sciences Center Animal Research Committee. Efforts were made to minimize animal stress and discomfort. Brains were removed and neurons were isolated by trypsin treatment. After trituration and plating onto poly-L-lysine-coated glass coverslips in MEM with 15\% horse serum at a density of $10,000-100,000$ cells $/ 35 \mathrm{~mm}^{2}$, cells were transferred to glial culture dishes to grow over a glial cell monolayer in serum-free MEM with N2 supplements. Neuronal culture coverslip preparation consisted of primarily pyramidal neurons easily distinguished morphologically from the $\sim 7 \%$ of GABAergic interneurons (Benson et al., 1994). For chronic treatment with elevated extracellular potassium, neurons were grown in media with a $7 \mathrm{~mm}\left[\mathrm{~K}^{+}\right]$increase with $\mathrm{KCl}$ for $48 \mathrm{~h}$ after $12-13$ days in vitro (DIV). Electrophysiology recordings and immunocytochemistry experiments were performed at 14 or 15 DIV and all experimental treatments were performed with parallel control cultures. This time point was selected because GABAergic synapses have developed and plasticity of synapses can be observed (Swanwick et al., 2006a,b). All chemicals were from Sigma-Aldrich unless stated otherwise.

Electrophysiology. GABAergic currents were recorded from cultured hippocampal neurons using whole-cell patch-clamp methods previously described (Mangan and Kapur, 2004). Membrane properties and synaptic currents of 14 DIV hippocampal neurons from these cultures have been previously characterized (Mangan and Kapur, 2004; Swanwick et al., 2006b). Thick-walled ( $1.5 \mathrm{~mm}$ inner, $0.86 \mathrm{~mm}$ outer diameter) borosilicate patch electrodes (World Precision Instruments) were pulled to a low final resistance of 2-5 $\mathrm{M} \Omega$ using a two-stage pull on a P-97 FlamingBrown horizontal puller (Sutter Instruments). Pyramidal neurons were visually identified by their morphology with an inverted microscope and experiments were done at room temperature. IPSC recordings were made with patch electrodes filled with a recording solution that contained (in mM): $153.3 \mathrm{CsCl}, 1.0 \mathrm{MgCl}_{2}, 5.0$ EGTA, and 10.0 HEPES, with a pH of 7.20 and osmolarity of $290-300 \mathrm{mOsm}$. CsCl was included to block potassium currents. MgATP (4 mM) was added to the intracellular solution before recording. The external solution for recordings contained (in mM): $146.0 \mathrm{NaCl}, 2.5 \mathrm{KCl}, 3.0 \mathrm{MgCl}_{2}, 2.0 \mathrm{CaCl}_{2}, 10.0$ glucose, and 10.0 HEPES, with a pH of 7.40 and osmolarity of 315-330 mOsm. Internal and external recording solutions contained equimolar concentrations of chloride ions, and at a clamped membrane potential of $0 \mathrm{mV}$, no $\mathrm{GABA}_{\mathrm{A}}$ receptor-mediated mIPSCs were present. For recording mIPSCs, glutamate receptor-mediated synaptic currents were blocked by 50 $\mu \mathrm{M}$ D-APV and $20 \mu \mathrm{M}$ DNQX in the external solution, along with $1 \mu \mathrm{M}$ tetrodotoxin in the external solution blocking action potentials. Neurons were voltage-clamped to $-60 \mathrm{mV}$. $\mathrm{GABA}_{\mathrm{A}}$ antagonist bicuculline $(5 \mu \mathrm{M})$ was bath applied and elimination of observed currents demonstrated that GABAergic currents were recorded.

For loose patch firing rate recordings, the internal patch pipette solution was the same as the external recording solution. In high potassium recordings, the external recording solution contained $7 \mathrm{mM} \mathrm{KCl}$ and patch pipettes were filled with this external solution. Osmolarity for both control external solution with $2.5 \mathrm{~mm} \mathrm{KCl}$ and high potassium external solution was adjusted to $320 \mathrm{mOsm}$ before experiments. Resistance and capacitance were compensated for each neuron, and recordings were rejected if the series resistance after compensation was $\geq 20 \mathrm{M} \Omega$. Currents were recorded at $I=0$ with an Axopatch 200A amplifier (Molecular Devices) and low-pass filtered at $2 \mathrm{kHz}$ with an 8 -pole Bessel filter before digitization, storage, and display. Currents were digitized at $400 \mathrm{~Hz}$ using a Digidata 1322 digitizer and acquired with Axoscope software (Molecular Devices) on an IBM PC-compatible hard drive.

Surface receptor detection and Western blotting. Surface expression of $\gamma 2$ subunit-containing $\mathrm{GABA}_{\mathrm{A}}$ receptors was studied by biotinylation assay modified from previous studies (Goodkin et al., 2008; Joshi and Kapur, 2009). Neuron cultures were incubated in ice-cold ACSF containing $1 \mathrm{mg} / \mathrm{ml}$ sulfo-NHS-LC-biotin (Thermo Fisher Scientific) for $30 \mathrm{~min}$ at $4^{\circ} \mathrm{C}$ with gentle shaking. Unbound biotin was removed by washing the neurons twice in TBS (containing, in mM: 25 Tris, pH 7.4, $137 \mathrm{NaCl}, 5$ $\mathrm{KCl}, 2.3 \mathrm{CaCl}_{2}$, and $0.5 \mathrm{MgCl}_{2}$ ). Cells were removed from dishes and suspended in ice-cold RIPA lysis buffer containing $1 \mathrm{~mm}$ sodium orthovanadate and Protease Inhibitor Cocktail set I (EMD Chemicals). The lysates were cleared by centrifugation at $14,000 \times g$ for $15 \mathrm{~min}$. Lysates with $160 \mu \mathrm{g}$ of total protein were incubated with $100 \mu \mathrm{l}$ of neutravidinagarose beads (Thermo Fisher Scientific) for $2 \mathrm{~h}$ at $4^{\circ} \mathrm{C}$ to purify biotinbound surface proteins from biotin-unbound cytosolic proteins. Beads were washed three times with RIPA-lysis buffer, proteins eluted in nonreducing sample buffer, and sample denatured at $95^{\circ} \mathrm{C}$ for $5 \mathrm{~min}$. Surface and total expression were detected by Western blotting. In addition to surface protein samples, lysates with $30 \mu \mathrm{g}$ of protein were analyzed for the total $\mathrm{GABA}_{\mathrm{A}}$ receptor subunit expression. The proteins were subjected to electrophoresis using 10\% SDS polyacrylamide gels and transferred to a Hybond-P PVDF membrane. The membrane was blocked in $5 \%$ nonfat dry milk in TBST for $2 \mathrm{~h}$ at room temperature and incubated with a monoclonal anti-GABA $\mathrm{A}_{\mathrm{A}}$ receptor $\gamma 2$ subunit antibody (Joshi et al., 2011) directed against the $\mathrm{N}$ terminus (1:1000 in TBST, $1 \% \mathrm{BSA}$ ) overnight at $4^{\circ} \mathrm{C}$ with shaking. Following incubation with HRPconjugated secondary antibody (1:2000) blots were developed using Western lightning chemiluminescence reagent plus kit and detected using a Kodak gel Logic 2200 imaging system. Absence of contaminating cytoplasmic proteins in the biotinylated samples was confirmed by reprobing blots with anti $\beta$-actin antibody (1:5000). Signal intensity was determined by densitometric scanning and ratio of surface/total proteins was calculated.

Immunocytochemistry. Hippocampal cultures were fixed at 14-15 days in vitro with $4 \%$ paraformaldehyde/4\% sucrose in PBS, $\mathrm{pH} 7.1$, for 20 min at room temperature, blocked with $4 \%$ normal goat serum for 15 $\mathrm{min}$ at room temperature, and incubated with anti-GABA $\mathrm{A}_{\mathrm{A}}$ receptor $\gamma 2$ subunit antibody $(0.5 \mu \mathrm{g} / \mathrm{ml}$, monoclonal, Kapur Laboratory) overnight at $4^{\circ} \mathrm{C}$. Coverslips were washed with $1 \times \mathrm{PBS}$, permeabilized with $0.10 \%$ Triton X-100 in PBS for 15 min at room temperature, and incubated again overnight at $4^{\circ} \mathrm{C}$ with a second primary antibody, a rabbit monoclonal antibody against GAD-6 clone to recognize GAD-65 $(1 \mu \mathrm{g} / \mathrm{ml}$, Millipore). Coverslips were again washed with $1 \times$ PBS and incubated with the fluorochrome-conjugated secondary antibodies for $45 \mathrm{~min}$ while shaking at room temperature in darkness. Coverslips were mounted in Gel/Mount (Biomedia Corp.), the edge of each coverslip were sealed with clear nail polish and stored at $-20^{\circ} \mathrm{C}$ after imaging. Secondary antibodies included Alexa Fluor 488 and Alexa Fluor 594 fluorochromes conjugated with goat anti-mouse or goat anti-rabbit IgG ( $4 \mu \mathrm{g} / \mathrm{ml}$, Invitrogen). All primary and secondary antibodies were diluted in $1 \times$ PBS containing $2 \%$ normal goat serum.

To study the rate of receptor turnover from the cell membrane over time, an antibody feeding technique was used and the surface fraction of receptors was observed as described previously (Goodkin et al., 2008). Surface receptors were labeled by incubating cells with anti-GABA $\mathrm{A}$ receptor $\gamma 2$ subunit antibody $(10 \mu \mathrm{g} / \mathrm{ml})$ for $1 \mathrm{~h}$ at $4^{\circ} \mathrm{C}$. Briefly, coverslips were washed with PBS to remove excess, unbound antibody and then incubated at $37^{\circ} \mathrm{C}$ for $0-60 \mathrm{~min}$ to allow intracellular receptor accumulation. Coverslips were then fixed with $4 \%$ paraformaldehyde/ $4 \%$ sucrose in PBS, pH 7.1, labeled with secondary antibody, and mounted as previously described.

Image acquisition and analysis. Fluorescent and bright-field images were captured on a Roper Scientific Photometrics CoolSNAPcf CCD camera mounted on a Nikon Eclipse TE200 fluorescent microscope 
A
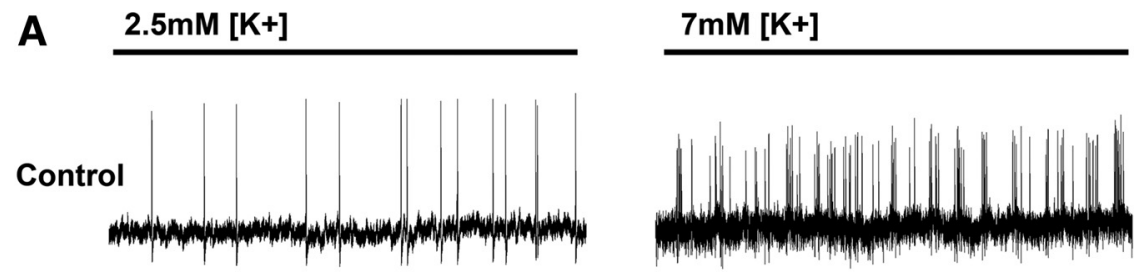

$7 \mathrm{mM}[\mathrm{K}+]$

$2.5 \mathrm{mM}[\mathrm{K}+]$

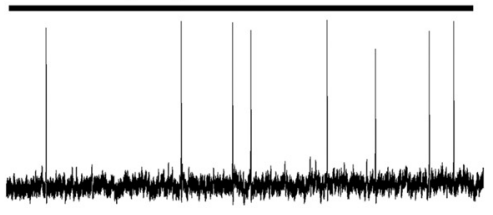

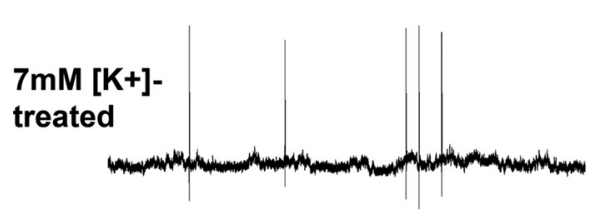

B

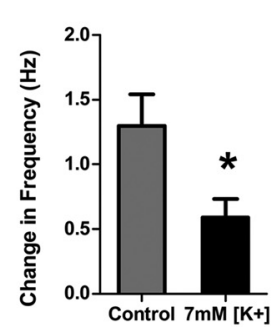

C Control

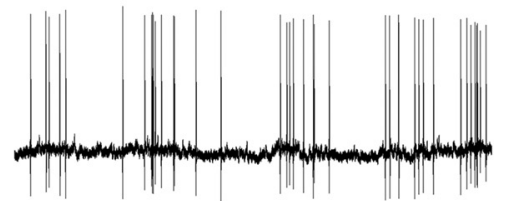

$7 \mathrm{mM}[\mathrm{K}+]$-treated

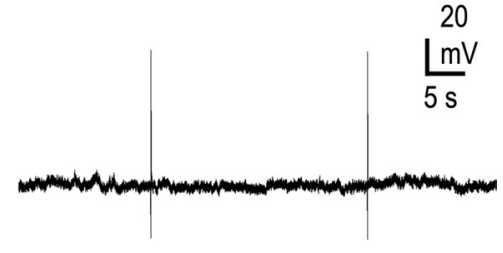

20

Figure 1. Action potential firing rate of neurons homeostatically stabilized after depolarization-induced increase. $\boldsymbol{A}$, One minute traces show action potentials from representative untreated control and $7 \mathrm{~mm}\left[\mathrm{~K}^{+}\right]$-treated neurons before, during, and after acute depolarization with $7 \mathrm{~mm}\left[\mathrm{~K}^{+}\right]$external solution. $\boldsymbol{B}$, The action potential firing rate increased in response to acute depolarization and was smaller in $7 \mathrm{~mm}\left[\mathrm{~K}^{+}\right]$-treated neurons than in controls. Loose patch recordings were obtained from untreated control neurons and from neurons that had been grown in medium treated with an elevated $7 \mathrm{~mm}\left[\mathrm{~K}^{+}\right]$. C, $\boldsymbol{D}$, One minute traces from representative untreated control and $7 \mathrm{~mm}\left[\mathrm{~K}^{+}\right]$-treated neurons $(\boldsymbol{C})$ show similar action potential firing rates $(\boldsymbol{D})$. Recordings from $7 \mathrm{~mm}\left[\mathrm{~K}^{+}\right]$-treated neurons were performed in external medium with $7 \mathrm{~mm}\left[\mathrm{~K}^{+}\right]$, whereas those from control neurons were in standard external medium containing $2.5 \mathrm{~mm}\left[\mathrm{~K}^{+}\right]$. ${ }^{*} p<0.05$.

equipped with a mercury lamp and driven by MetaMorph imaging software (Molecular Devices). High resolution digital images were acquired with a $60 \times 1.4$ numerical aperture lens for each fluorochrome from morphologically intact neurons. Punctate fluorescence was thresholded using MetaMorph imaging software. For colocalization, binary images were created from thresholded images and then added together to display overlapping puncta of different fluorochromes from the same cell. The reported colocalized puncta size represents the measured area of overlap between the fluorochromes. Data were analyzed using GraphPad Prism 5 , and all values of puncta size, number, and area of colocalization are reported as mean \pm SEM. Values comparing two experimental groups were evaluated by two-tailed Student's $t$ test with a significance level of $p<0.05$. For multiple experimental time points, an ANOVA with post hoc Tukey's multiple-comparison test was used with a significance level of $p<0.05$. Images were saved as TIFF files and Adobe Photoshop CS5 was used to increase overall brightness for final production.

Electrophysiology analysis. MiniAnalysis software (Synaptosoft) was used to analyze frequency, amplitude, 10-90\% rise-time, and decay of miniature IPSCs. MiniAnalysis was also used to analyze the firing rate frequency in cell-attached recordings. The mIPSC detection threshold was three times the root mean square of the baseline noise $(\sim 5 \mathrm{pA})$, and the accuracy of detection was visually confirmed for each recording. Since the values for mIPSC amplitudes, $10-90 \%$ rise-times, and decay from each recorded neuron are not normally distributed and represent skewed populations, the medians were taken from each recording and averaged. Reported values for amplitude, $10-90 \%$ rise-time, and decay are the mean of the medians. The decay was analyzed by fitting individual currents with a biexponential curve of two time constants $\left(\tau_{1}\right.$ and $\left.\tau_{2}\right)$ and accepting the fit when $R^{2}>0.70$. Decay was obtained on the first 20 current traces fitting this criteria and displaying a rise time $<3 \mathrm{~ms}$. Frequency values were described as means. When applicable, SEM was reported. Values compared between two experimental groups were evaluated by two-tailed Student's $t$ test with a significance level of $p<$ 0.05 . For multiple experimental time points, an ANOVA with post hoc
Tukey's multiple-comparison test was used with a significance level of $p<0.05$.

\section{Results}

Homeostatic plasticity in cultured hippocampal neurons

Action potentials were recorded in loose-patch configuration from a hippocampal neuron that had grown for $14 \mathrm{~d}$ in control medium. The recording was made while the neuron was in a normal ACSF bath with a potassium concentration of $2.5 \mathrm{~mm}$, and then the bath was switched to an ACSF solution containing 7 $\mathrm{mm}\left[\mathrm{K}^{+}\right]$. The firing rate increased in response to the solution switch. Perfusion of normal ACSF reversed the firing rate back to baseline (Fig. 1A, top). This result suggested that the addition of $7 \mathrm{~mm} \mathrm{KCl}$ growth media could similarly increase the firing rate of hippocampal neurons in culture. To determine the impact of elevated extracellular potassium on the excitability of neurons, we added $7 \mathrm{~mm} \mathrm{KCl}$ to the culture medium of hippocampal neurons for a period of $48 \mathrm{~h}$, while control neurons were maintained in untreated medium. The experiment measuring the response to an acute change in potassium concentration was then performed on a $7 \mathrm{mM}\left[\mathrm{K}^{+}\right]$-treated neuron. Similarly, switching the external ACSF from $2.5 \mathrm{~mm}\left[\mathrm{~K}^{+}\right]$to $7 \mathrm{mM}\left[\mathrm{K}^{+}\right]$increased the firing rate of the $7 \mathrm{~mm}\left[\mathrm{~K}^{+}\right]$-treated neuron. Although a similar pattern of increased activity level was observed in both control and treated neurons, the firing rate of the treated neuron appeared to increase less than the firing rate of the control neuron (Fig. $1 A$, bottom). We repeated this switch in eight control neurons and found the mean firing frequency increased by $1.3 \pm 0.24 \mathrm{~Hz}$ (Fig. $1 B$ ). The firing frequency in nine treated neurons had a smaller increase, rising $0.59 \pm 0.14 \mathrm{~Hz}$ ( $t$ test, $p<0.05$ ) in response to the switch (Fig. $1 B$ ). In both control and treated cultures, firing rates re- 


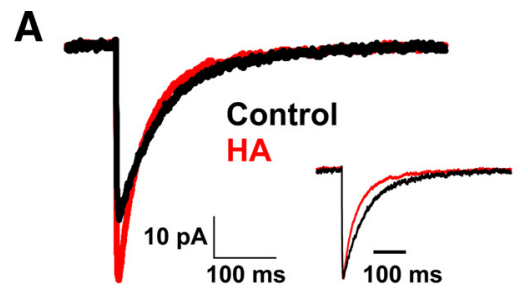

C

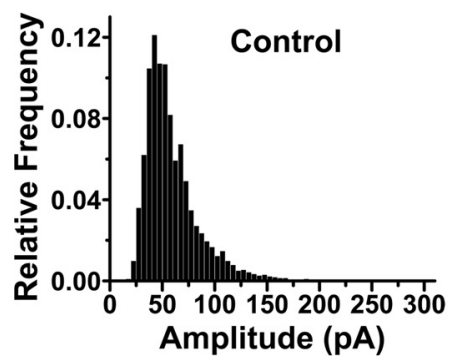

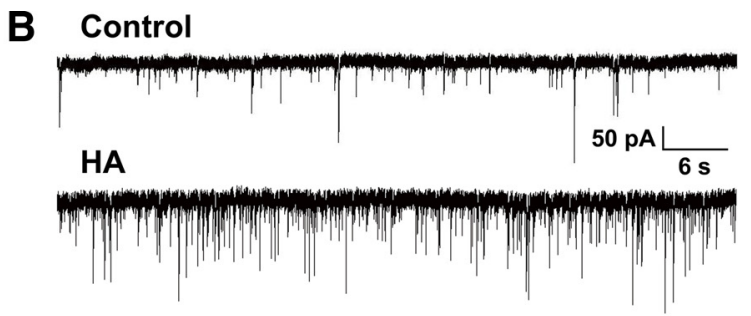

D
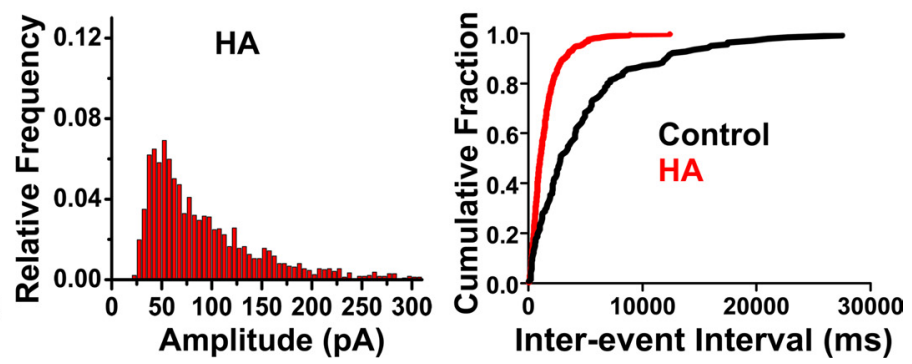

Figure 2. High activity treatment increased amplitude and frequency of mIPSCS. $A$, Trace of averaged mIPSCs from a representative HA-treated neuron had a larger amplitude than that from an untreated neuron (inset, normalized traces). $\boldsymbol{B}$, One minute recordings from representative HA-treated and untreated neurons. $\boldsymbol{C}$, Normalized mIPSC amplitude distribution histograms from representative HA-treated and untreated neurons revealed a shift toward higher amplitude events after HA treatment. $\boldsymbol{D}$, Cumulative probability plot of mIPSC frequency from representative HA-treated and untreated neurons demonstrating a shift toward higher frequency of events after HA treatment.

turned to baseline levels when $2.5 \mathrm{~mm}\left[\mathrm{~K}^{+}\right]$ACSF was perfused back into the recording bath (Fig. $1 A$ ). The ratios for the relative increase over baseline calculated for nine individual $7 \mathrm{mM}\left[\mathrm{K}^{+}\right]$treated neurons $(18 \pm 9.0, n=9)$ was similar to the relative increase in control neurons $(19 \pm 7.0, n=9, p=0.9)$. These data suggest that the magnitude of response to acute changes in excitability of $7 \mathrm{~mm}\left[\mathrm{~K}^{+}\right]$-treated neurons is smaller than that of control neurons; however, the magnitude of this change is scaled relative to an overall shift in excitability. This supports the possibility that mechanisms of homeostatic plasticity scale neuronal excitability while maintaining a stable relative response to acute perturbations in firing.

Homeostatic plasticity theory predicts that the action potential firing rate of a hippocampal neuron stabilizes in the face of a chronic increase in excitation. To test this hypothesis, action potentials were first recorded from a hippocampal neuron that had grown for $14 \mathrm{~d}$ in control medium. In a normal ACSF bath with a potassium concentration of $2.5 \mathrm{~mm}$ it displayed an action potential firing rate of $0.18 \mathrm{~Hz}$ over $5 \mathrm{~min}$ (Fig. $1 C$ ). We then recorded from a neuron which had been in culture for $14 \mathrm{~d}$ with the final $48 \mathrm{~h}$ in a medium supplemented with $7 \mathrm{~mm}\left[\mathrm{~K}^{+}\right]$. This loose patch recording from the treated neuron was performed in an ACSF bath with $7 \mathrm{~mm}\left[\mathrm{~K}^{+}\right]$, and the neuron displayed a firing rate of $0.19 \mathrm{~Hz}$ over $5 \mathrm{~min}$ of recording (Fig. 1C). In a group of 7 $\mathrm{mM}\left[\mathrm{K}^{+}\right]$-treated neurons $(n=8)$ recorded in $7 \mathrm{mM}\left[\mathrm{K}^{+}\right]$, the frequency of action potentials was $0.20 \pm 0.03 \mathrm{~Hz}$. The frequency of firing in 16 control neurons from cultures grown in parallel was $0.22 \pm 0.06 \mathrm{~Hz}(p=0.8$, unpaired $t$ test, Fig. $1 D)$. This suggested that the frequency of action potentials in $7 \mathrm{~mm}\left[\mathrm{~K}^{+}\right]$treated neurons was similar to that in neurons grown in control conditions.

Thus, increasing extracellular potassium acutely increases the neuronal firing rate, although, the rate appeared to return a baseline level after $48 \mathrm{~h}$. Furthermore, the $7 \mathrm{~mm}\left[\mathrm{~K}^{+}\right]$-treated neurons responded to acute treatment with high potassium with a smaller increase in firing rate than control neurons. These results establish that homeostatic plasticity mechanisms regulating the firing rate of neurons in culture were activated by $48 \mathrm{~h}$ treatment with 7 $\mathrm{mm}\left[\mathrm{K}^{+}\right]$. While the firing rate may stabilize, the depolarizing conditions driving the initial increase in neuronal excitability persist throughout the $48 \mathrm{~h}$. Since the $7 \mathrm{~mm}\left[\mathrm{~K}^{+}\right]$initially increases the firing rate of neurons in culture and induces the activity-dependent homeostatic responses, this treatment will be referred to as high activity or HA.

Increased GABAergic synaptic strength after chronic increase in neuronal excitability

The homeostatic plasticity hypothesis predicts an increase in inhibitory synaptic strength when the neuron is challenged with an increased neuronal firing rate. To investigate the strength of inhibitory synapses in an HA-treated neuron, mIPSCs were recorded using whole-cell voltage-clamp techniques to measure synaptic GABAergic transmission.

The mIPSCs recorded from a neuron after $48 \mathrm{~h}$ of HA treatment were larger in amplitude than those from a control neuron recorded on the same day (Fig. $2 A, B$ ). This finding was replicated and data from all treated neurons were pooled for statistical analysis. The median amplitude obtained from each experiment was used for pooling data as the amplitudes of mIPSCs were not a normally distributed population (Fig. $2 C$ ). The mean of the median amplitudes of mIPSCs in HA-treated neurons was $55 \%$ greater than that of mIPSCs recorded from control neurons (Table 1 ).

The mIPSCs also displayed a higher frequency in HA-treated neurons than in control neurons. A cumulative frequency plot of the interevent intervals of mIPSCs recorded from a control and a HA-treated neuron revealed a shift toward shorter interevent intervals in the treated neuron (Fig. 2D). The mean frequency of mIPSCs recorded from 11 HA-treated neurons was higher than that obtained from control neurons (Table 1). These findings were consistent with previous studies that suggested presynaptic mechanisms may contribute to activity-dependent changes in inhibitory synaptic strength (Hartman et al., 2006; Swanwick et al., 2006a; Peng et al., 2010). 
Table 1. mIPSC kinetics for control and treated neurons

\begin{tabular}{lllll}
\hline & $\begin{array}{l}\text { Amplitude } \\
(\mathrm{pA})\end{array}$ & $\begin{array}{l}\text { Frequency } \\
(\mathrm{Hz})\end{array}$ & $\begin{array}{l}10-90 \% \\
\text { Rise time }\end{array}$ & $\tau_{\mathrm{w}}$ \\
\hline Control $(n=18)$ & $42.5 \pm 1.4$ & $0.3 \pm 0.05$ & $1.5 \pm 0.06$ & $61.2 \pm 3.6$ \\
$6 \mathrm{~h}(n=7)$ & $40.2 \pm 3.8$ & $0.4 \pm 0.1$ & $1.7 \pm 0.11$ & $46.5 \pm 5.2$ \\
$12 \mathrm{~h}(n=11)$ & $52.8 \pm 2.2^{*}$ & $0.3 \pm 0.05$ & $1.4 \pm 0.09$ & $57.9 \pm 6.3$ \\
$24 \mathrm{~h}(n=9)$ & $65.4 \pm 2.8^{* *}$ & $0.4 \pm 0.1$ & $1.1 \pm 0.10$ & $57.3 \pm 6.4$ \\
$48 \mathrm{~h}(n=11)$ & $66.1 \pm 4.4^{* *}$ & $0.6 \pm 0.1^{* *}$ & $1.4 \pm 0.19$ & $37.7 \pm 7.5^{*}$ \\
\hline
\end{tabular}

${ }^{*} p<0.05,{ }^{* *} p<0.005$, ANOVA with post hoc Tukey's multiple-comparison test, $n=$ number of neurons.

\section{GABAergic mIPSC amplitude increase precedes frequency increase}

The homeostatic mechanisms that lead to changes in synaptic strength may depend upon cellular processes occurring over different timescales. To further determine which potential mechanisms drive these synaptic changes, shorter intervals of HA treatment were studied. After $6 \mathrm{~h}$ of HA treatment, the mIPSCs recorded were similar to those in a representative control (Fig. $4 A$ ). This similarity to control neurons did not remain though, as GABAergic mIPSCs were significantly larger in amplitude after $12 \mathrm{~h}$ of HA treatment. At $24 \mathrm{~h}$, the mIPSC amplitudes were also larger than controls and were similar in size to the increased amplitudes found at $48 \mathrm{~h}$ (Table 1). The mean frequency of currents was analyzed at each time point and did not change after 6,12, or $24 \mathrm{~h}$ of HA treatment (Table 1). Thus, the amplitude of mIPSCs increased after $12 \mathrm{~h}$ of HA treatment and continued to increase until it reached a peak value at $24 \mathrm{~h}$ (Fig. 4A), whereas the frequency of these currents increased significantly only at $48 \mathrm{~h}$ of HA treatment (Fig. $4 B$ ). The change in weighted decay of mIPSCs found at $48 \mathrm{~h}$ was not present at any other time point during treatment, and rise time values were similarly found to be unchanged throughout the HA treatment (Table 1).

Figure 3. Firing rate of HA-treated neurons increases when inhibitory transmission is reduced to control levels. $A$, Traces of averaged $\mathrm{mIPSC}$ from representative neurons after $48 \mathrm{~h}$ of $\mathrm{HA}$ treatment (left, center) along with a trace of averaged $\mathrm{mIPSC}$ from an untreated control neuron (right). Application of $0.1 \mu \mathrm{m}$ bicuculline in the external solution during a whole-cell recording reduced the amplitude of mIPSCs of an HA-treated neuron to control levels (center). $\boldsymbol{B}$, The firing rate of HA-treated neurons significantly increases when inhibitory transmission is reduced to the level of untreated controls using $0.1 \mu \mathrm{m}$ bicuculline.

\section{High activity leads to increase in synaptic $\mathrm{GABA}_{\mathrm{A}}$ receptors}

Previous work has suggested that reduced

The rise time, amplitude, and decay of an MIPSC are shaped by the kinetic properties of the $\mathrm{GABA}_{\mathrm{A}}$ receptor (Maconochie et al., 1994; Jones and Westbrook, 1995; Bianchi and Macdonald, 2001). At $48 \mathrm{~h}$, the kinetics of mIPSCs recorded from HA-treated neurons were distinct from control neurons. While the $10-90 \%$ rise time was found to be unchanged, the weighted decay component $\tau_{\mathrm{w}}$, was faster in HA-treated neurons when compared with control neurons (Table 1).

\section{Increased GABAergic synaptic strength is necessary for firing rate stability after $\mathrm{HA}$}

While the increase in GABAergic synaptic strength corresponded to the stabilization of the firing rate after $48 \mathrm{~h}$ of HA treatment, many other synaptic and intrinsic processes are known to function in the homeostatic regulation of excitability in neurons. To determine whether increased inhibitory synaptic strength contributes directly to this stabilization, GABAergic transmission was reduced to control levels in the HA-treated neurons while recording firing rates (Fig. $3 A$ ). A low concentration of bicuculline $(0.1 \mu \mathrm{M})$ was applied during whole-cell voltage-clamp recordings of mIPSCs. The amplitude of HA-treated mIPSCs was reduced from $56.2 \pm 3.9 \mathrm{pA}$ to $40.0 \pm 3.1 \mathrm{pA}(n=7, p<0.005)$, similar to the amplitude of mIPSCs in control neurons (43.3 \pm $1.7, n=7, p=0.8$ ). When this concentration was acutely applied to HA-treated neurons being recorded in loose patch configuration, the firing rate significantly increased from $0.17 \pm 0.02-$ $1.2 \pm 0.3(n=14, p<0.005)$ (Fig. 3B). The HA-treated neurons, when reduced to control levels of GABAergic neurotransmission, do not maintain the stable homeostatic level of firing. synaptic strength after network activity blockade arises from presynaptic changes (Hartman et al., 2006). However, in addition to the quantity of presynaptic vesicle content (Frerking et al., 1995), increases in mIPSC amplitude can be attributed to an increase in the number of $\mathrm{GABA}_{\mathrm{A}}$ receptors at synapses (Nusser et al., 1997, 1998). The surface expression of these receptors was studied to determine whether an increases in the number of postsynaptic $\mathrm{GABA}_{\mathrm{A}}$ receptors leads to the increase in inhibitory synaptic strength in HA-treated neurons.

A biotinylation assay of surface proteins was used to isolate the surface population of $\gamma 2$ subunit-containing $\mathrm{GABA}_{\mathrm{A}}$ receptors. HA-treated cultures were found to express more $\gamma 2$ subunitcontaining $\mathrm{GABA}_{\mathrm{A}}$ receptors on the surface than control cultures (Fig. $5 B$ ). Interestingly, the total expression of the $\gamma 2$ subunit was similar in both HA-treated and control cultures (Fig. 5A). In seven replicates, the $\gamma 2$ surface expression was $214 \pm 23 \%$ of that in control cultures values $(p<0.05)$ (Fig. $5 D)$; whereas, the total expression of the $\gamma 2$ subunit in HA-treated was only $119 \pm 12 \%$ of control cultures $(n=7, p=0.5$, Fig. 5C). The increase in $\gamma 2$ subunit surface expression in biotinylation studies suggests that the observed increase in GABAergic synaptic strength after HA treatment was consistent with an increase in the number of postsynaptic receptors.

Although surface $\mathrm{GABA}_{\mathrm{A}}$ receptors increased after $\mathrm{HA}$ treatment, these studies did not reveal whether or not these surface receptors are present in synapses where they might functionally affect synaptic strength. This possibility was directly tested through double-label immunocytochemistry. 
A

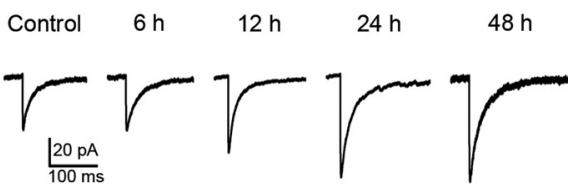

B
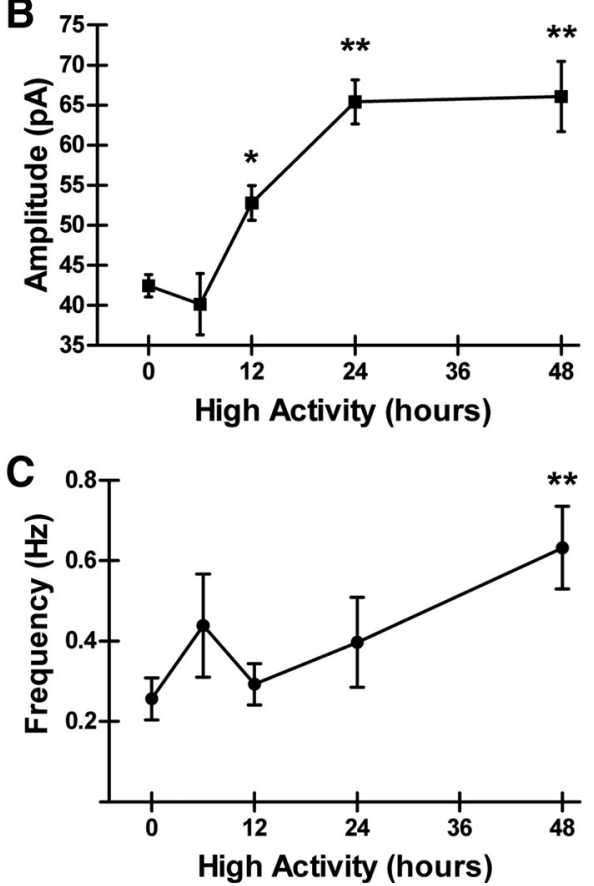

Figure 4. mIPSC amplitude increased before frequency increased during HA treatment. $A$, Traces of averaged mIPSCs from representative neurons after 6, 12, 24, and $48 \mathrm{~h}$ of HA treatment, and from untreated control neuron. $\boldsymbol{B}$, After $12 \mathrm{~h}$ of HA treatment, $\mathrm{mIPSC}$ amplitude was larger than in untreated controls. Larger amplitudes are also observed after 24 and $48 \mathrm{~h}$ of HA treatment. C, Increased mIPSC frequency occurred at $48 \mathrm{~h}$ of HA treatment (see Table 1 for details). ${ }^{*} p<0.05 ;{ }^{* *} p<0.005$.

The $\gamma 2$ subunit of the GABAergic receptor was used to localize synaptic $G_{A B A}$ receptors, as this subunit is necessary for clustering and synaptic targeting of the $\mathrm{GABA}_{\mathrm{A}}$ receptors (Essrich et al., 1998). The $65 \mathrm{kDa}$ isoform of glutamic acid decarboxylase (GAD-65) was used as a presynaptic marker, as it is found in presynaptic terminals of GABAergic synapses (Mi et al., 2002).

The $\mathrm{GABA}_{\mathrm{A}}$ receptor clusters present on HA-treated neurons were larger than those on control neurons (Fig. 6A-E). As described in previous studies, large clusters of receptors can colocalize at synapses with the presynaptic marker GAD-65 (Rao et al., 2000; Christie et al., 2002; Swanwick et al., 2006b). In addition to the appearance of both larger $\mathrm{GABA}_{\mathrm{A}}$ receptor clusters and larger GAD-65 puncta in HA-treated cells (Fig. $6 A-D, F-I)$, puncta of the colocalized areas between the two markers also visibly increased in size with HA treatment (Fig. $6 K-N)$. Quantification of the surface $\mathrm{GABA}_{\mathrm{A}}$ receptor $\gamma 2$ subunit clusters in HA-treated neurons showed a significant increase in cluster size compared with control neurons (Fig. $6 E$, Table 2). In addition, GAD-65 puncta size was also larger in HA-treated neurons versus control neurons (Fig. 6J, Table 2). Analysis of colocalization between these postsynaptic and presynaptic markers also revealed that the size of synaptically localized $\gamma 2$ subunit puncta in HA-treated neurons was larger than in control neurons (Fig. 60, Table 2).
A Total

Control HA
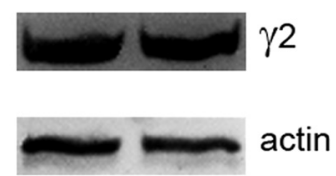

C

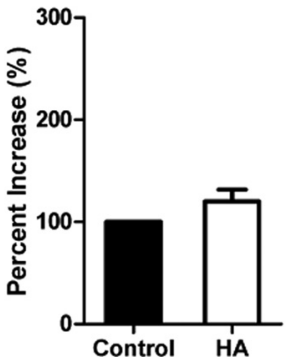

B Surface
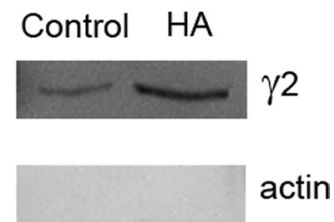

D

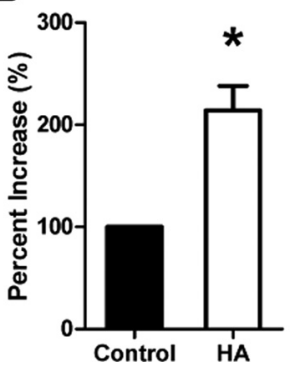

Figure 5. GABAR $\gamma 2$ subunit surface expression increased in $\mathrm{HA}$-treated neurons while total expression remained unchanged. $A, B, A$ biotinylation assay was used to label surface GABARs containing the $\gamma 2$ subunit, and both surface and total $\gamma 2$ subunit protein expression were measured by Western blot. Blots were reprobed with an actin antibody. A representative blot shows total expression of the $\gamma 2$ subunit was similar in both HA-treated and control sample $(\boldsymbol{A})$, whereas surface expression of the $\gamma 2$ subunit was significantly higher in $\mathrm{HA}$-treated samples (B). C, Total expression of the $\gamma 2$ subunit in HA-treated samples expressed as a percentage fraction of control $\gamma 2$ subunit expression. $D$, Surface expression of the $\gamma 2$ subunit in HA-treated samples expressed as a percentage fraction of control $\gamma 2$ subunit expression. ${ }^{*} p<0.05$.

$\mathrm{GABA}_{\mathrm{A}}$ receptor increase precedes presynaptic GAD increase during high activity

The increase in synaptic strength measured by mIPSC amplitude occurred earlier in the course of HA treatment compared with the observed change in frequency of mIPSCs, which suggested synaptic receptors upregulate before presynaptic changes. Therefore, immunocytochemistry was used to examine a possible correlation between changes in synaptic puncta and changes in synapse strength during the time course of change in synaptic strength over the $48 \mathrm{~h}$ HA treatment (Fig. 7A).

The postsynaptic marker $\mathrm{GABA}_{\mathrm{A}}$ receptor $\gamma 2$ subunit puncta size was significantly larger in neurons after $6 \mathrm{~h}$ of HA treatment compared with puncta in control neurons. This increase was maintained for the remainder of the time points through $48 \mathrm{~h}$ (Fig. 7B, Table 2). In contrast, the increase in GAD-65 puncta size had a delayed onset compared with the postsynaptic receptor puncta increase during HA treatment. A significant increase of GAD-65 puncta size was not observed until $24 \mathrm{~h}$ of HA treatment (Fig. $7 B$ ). This increase at $24 \mathrm{~h}$ was maintained at a similar level through the $48 \mathrm{~h}$ time point (Table 2).

$\mathrm{GABA}_{\mathrm{A}}$ receptor $\gamma 2$ subunit puncta that colocalized with the presynaptic marker GAD-65 puncta size at $6 \mathrm{~h}$ of HA treatment were similar to control puncta. However, at $12 \mathrm{~h}$ of HA treatment, colocalized puncta were significantly larger than control puncta (Table 2). Beyond $12 \mathrm{~h}$ of HA treatment, colocalized puncta maintained the trend toward increased size (Fig. $7 B$ ). The increase in colocalized puncta size at $12 \mathrm{~h}$ of HA treatment corresponds to the change in IIPSC amplitude also found at $12 \mathrm{~h}$ of HA treatment. The data suggest that the time course of increase in both colocalized puncta size and MIPSC amplitude follow parallel trends increasing further at $24 \mathrm{~h}$ and maintaining that increase through the $48 \mathrm{~h}$ of HA treatment. 

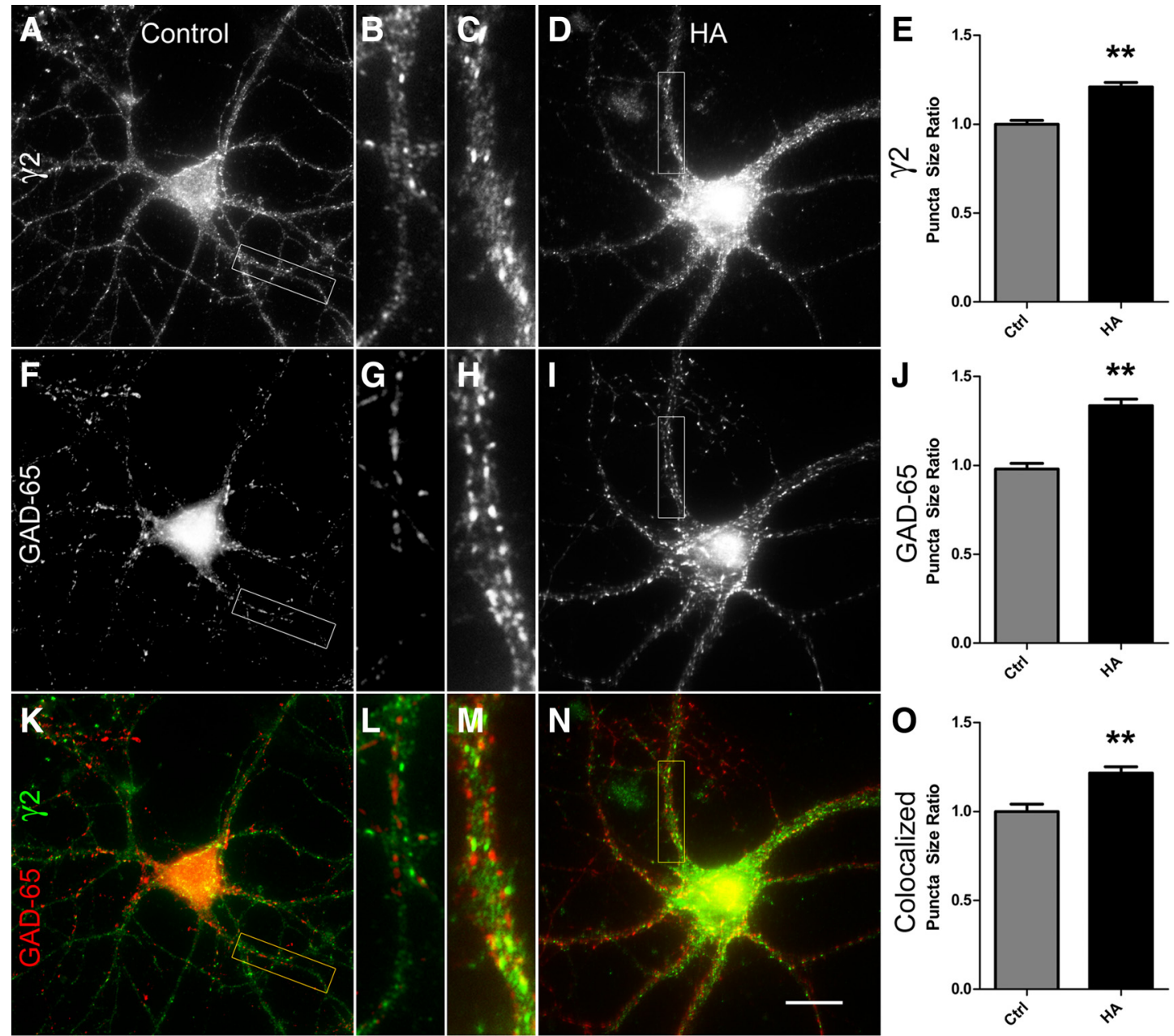

Figure 6. Both postsynaptic and presynaptic elements of $G A B A$ ergic synapses were larger after $48 \mathrm{~h}$ of $\mathrm{HA}$ treatment. $A-E$, Clusters of $G A B A R$ immunoreactivity on the surface of untreated control neurons $(\boldsymbol{A}, \boldsymbol{B})$ and $\mathrm{HA}$-treated neurons $(\boldsymbol{C}, \boldsymbol{D})$. $\gamma 2$ clusters were larger after $48 \mathrm{~h}$ of HA treatment $(\boldsymbol{E})$. $\boldsymbol{F}-\boldsymbol{J}, \mathrm{GAD}-65$ immunoreactivity in untreated control neurons $(\boldsymbol{F}, \boldsymbol{G})$ and in $\mathrm{HA}$-treated neurons $(\boldsymbol{H}, \boldsymbol{I})$. GAD-65 puncta were larger after $48 \mathrm{~h}$ of HA treatment $(\boldsymbol{J}) . \boldsymbol{K}-\mathbf{0}, \gamma 2$ clusters colocalized with GAD-65 puncta in untreated neurons $(\boldsymbol{K})$ (magnified inset, $\boldsymbol{L})$ and in HA-treated neurons $(\boldsymbol{M})$ (magnified inset, $\boldsymbol{N}$ ). Colocalized puncta were larger after $48 \mathrm{~h}$ of HA treatment (0). Scale bar, $20 \mu \mathrm{m} .{ }^{* *} p<0.005$.

Table 2. Sizes of GABAergic postsynaptic and presynaptic markers and colocalization

\begin{tabular}{llll}
\hline & $\gamma 2$ & GAD-65 & Colocalized \\
\hline Control $(n=48)$ & $18.3 \pm 0.7$ & $57.0 \pm 1.5$ & $28.1 \pm 1.2$ \\
$6 \mathrm{~h}(n=39)$ & $22.1 \pm 0.5^{* *}$ & $53.9 \pm 1.3$ & $29.2 \pm 0.9$ \\
$12 \mathrm{~h}(n=39)$ & $21.7 \pm 0.5^{* *}$ & $54.9 \pm 1.1$ & $32.7 \pm 1.3^{*}$ \\
$24 \mathrm{~h}(n=66)$ & $23.4 \pm 0.4^{* *}$ & $70.4 \pm 1.5^{* *}$ & $35.5 \pm 0.6^{* *}$ \\
$48 \mathrm{~h}(n=45)$ & $22.1 \pm 0.5^{* *}$ & $76.2 \pm 2.1^{* *}$ & $34.3 \pm 1.0^{* *}$ \\
\hline
\end{tabular}

${ }^{*} p<0.05,{ }^{*} p<0.005$, ANOVA with post hoc Tukey's multiple-comparison test. Units $=\mu \mathrm{m}^{2}, n=$ number of neurons.

Although puncta size changed significantly over the course of $48 \mathrm{~h}$ during HA, the number of puncta remained similar throughout the treatment. There was no significant difference between the $\mathrm{GABA}_{\mathrm{A}}$ receptor $\gamma 2$ subunit puncta density in neurons after $48 \mathrm{~h}$ of HA treatment and the density in control neurons $(p=0.07)$. The puncta density was similar in controls and treated neurons at each time point during the HA treatment (Table 3). The density of GAD and colocalized puncta did not change after HA treatment ( $p=0.3$ and $p=0.08$, respectively). No significant difference was found in the puncta density at any of the earlier time points (Table 3 ).
HA treatment attenuates loss of synaptic strength during blockade of newly synthesized $\mathrm{GABA}_{\mathrm{A}}$ receptors

The total expression of $\mathrm{GABA}_{\mathrm{A}}$ receptors did not change after $\mathrm{HA}$ treatment (Fig. $5 A, C$ ). The lack of change in total protein suggests that altered trafficking of receptors, rather than the synthesis of new receptors, was the dominant mechanism behind the increased cluster size. Since the surface expression of receptors can be altered by both forward trafficking of receptors to the membrane and internalization of receptors away from the membrane, we selectively blocked forward trafficking to observe the rate of internalization in isolation. Forward trafficking was inhibited by brefeldin A ( $5 \mu \mathrm{g} / \mathrm{ml})$, a compound that collapses the Golgi complex, thus restricting receptor exit from the endoplasmic reticulum (Fujiwara et al., 1988; Lo et al., 2008). Without newly synthesized receptors being trafficked to the surface, the rate of internalization should be the prominent mechanism driving the level of receptor surface expression.

mIPSCs were recorded from a control neuron following incubation in medium containing brefeldin A for $90 \mathrm{~min}$. The amplitude of mIPSCs in a brefeldin A-treated control neuron was smaller than that in an untreated neuron (Fig. $8 A$ ). The mean of the median amplitudes of mIPSCs in brefeldin A-treated control neurons $(27.7 \pm 0.6 \mathrm{pA}, n=14)$ was $31 \%$ smaller than that of 

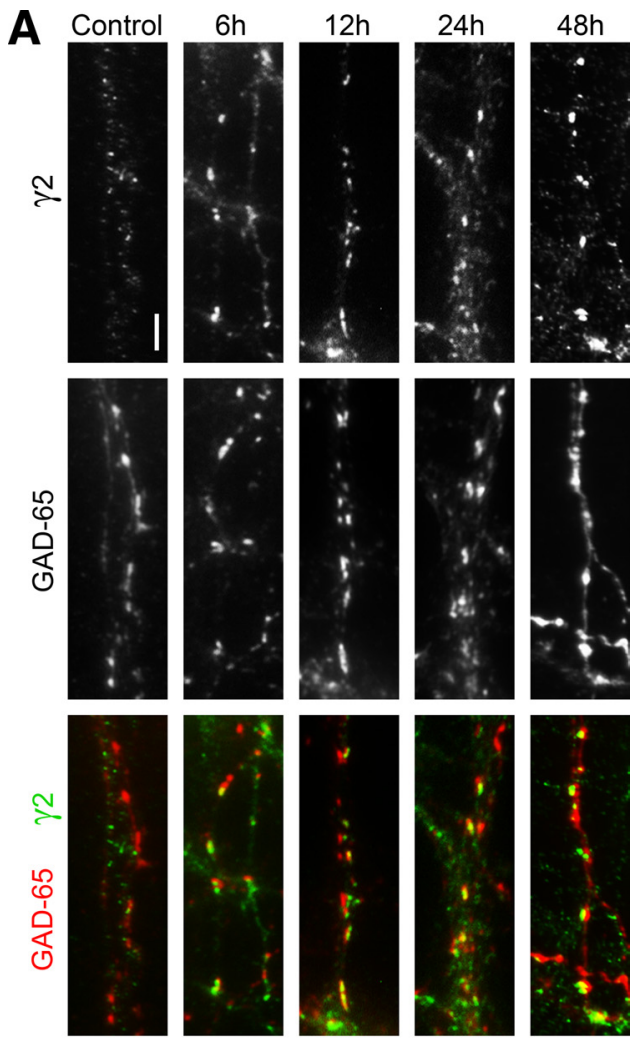

B

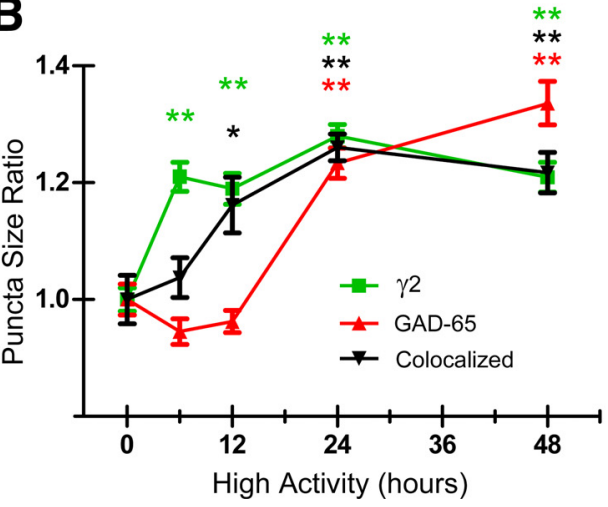

Figure 7. GABAR immunoreactivity increase precedes presynaptic GAD-65 increase during HA treatment. $\boldsymbol{A}$, $\gamma 2$ subunit-containing GABAR clusters, GAD-65 puncta, and colocalized puncta in neuronal dendrites. $\boldsymbol{B}, \gamma 2$ clusters were larger than controls at $6 \mathrm{~h}$ of $\mathrm{HA}$ treatment, GAD-65 were larger at $24 \mathrm{~h}$ of $\mathrm{HA}$ treatment, and colocalized puncta were larger at $12 \mathrm{~h}$ of $\mathrm{HA}$ treatment. All increases in puncta size were maintained at subsequent time points through the $48 \mathrm{~h}$ treatment. Scale bar, $10 \mu \mathrm{m} .{ }^{*} p<0.05 ;{ }^{* *} p<0.005$.

Table 3. Densities of GABAergic postsynaptic and presynaptic markers and colocalization

\begin{tabular}{llll}
\hline & $\gamma 2$ & GAD-65 & Colocalized \\
\hline Control $(n=48)$ & $2.5 \pm 0.1$ & $1.6 \pm 0.1$ & $0.8 \pm 0.1$ \\
$6 \mathrm{~h}(n=39)$ & $2.7 \pm 0.1$ & $1.8 \pm 0.1$ & $0.8 \pm 0.1$ \\
$12 \mathrm{~h}(n=39)$ & $2.3 \pm 0.1$ & $1.6 \pm 0.1$ & $0.8 \pm 0.1$ \\
$24 \mathrm{~h}(n=66)$ & $2.9 \pm 0.2$ & $1.7 \pm 0.1$ & $0.9 \pm 0.1$ \\
$48 \mathrm{~h}(n=45)$ & $2.9 \pm 0.1$ & $1.5 \pm 0.1$ & $0.9 \pm 0.1$ \\
\hline
\end{tabular}

${ }^{*} p<0.05,{ }^{* *} p<0.005$, ANOVA with post hoc Tukey's multiple-comparison test. Units = number per $10 \mu \mathrm{m}^{2}$, $n=$ number of neurons.

mIPSCs recorded from untreated control neurons $(40.1 \pm 1.0$ $\mathrm{pA}, n=14, p<0.005)$. We then added brefeldin A to an HAtreated culture for 90 min preceding $\mathrm{mIPSC}$ recording. The amplitude of mIPSCs in an HA-treated neuron after 90 min of brefeldin A was also smaller than the amplitude of HA-treated neurons that were not incubated with brefeldin A (Fig. 8B). However, in 14 HA-treated neurons the mean of median amplitudes of mIPSCs after brefeldin A treatment was $51.7 \pm 1.9 \mathrm{pA}$, a decrease of only $11 \%$ compared with HA-treated neurons without brefeldin A treatment $(58.1 \pm 1.9 \mathrm{pA}, n=14, p<0.05)$. The decrease in mIPSC amplitude after brefeldin A treatment appeared smaller in the HA-treated neurons, suggesting that a larger fraction of receptors remained at synapses during the brefeldin A treatment period in HA-treated neurons.

The surface expression of $\mathrm{GABA}_{\mathrm{A}}$ receptor $\gamma 2$ subunit after the 90 min brefeldin A treatment in both control (Fig. 8C) and HA-treated neurons (Fig. 8D) was studied. The $\mathrm{GABA}_{\mathrm{A}}$ receptor $\gamma 2$ subunit puncta in brefeldin A-treated control neurons were smaller $(29.3 \pm 0.9 \mu \mathrm{m}, n=30)$ than in untreated controls $(34.7 \pm 1.0 \mu \mathrm{m}, n=30 p<0.005)$. The $\gamma 2$ subunit puncta size were similar in HA-treated neurons both treated with brefeldin A $(41.0 \pm 1.0 \mu \mathrm{m}, n=30)$ and incubated without brefeldin A (43.2 $\pm 1.4 \mu \mathrm{m}, n=30, p=0.2)$. Again, the difference found in the HA-treated neurons was less that that found in controls. These findings suggest that receptors accumulate at the cell membrane during HA treatment; and furthermore, this accumulation appears to result primarily from a decrease in the rate of internalization, as a difference is found while blockading forward trafficking of recently synthesized receptors from the ER.

Reduced rate of $\mathrm{GABA}_{\mathrm{A}}$ receptor internalization contributes to homeostatic plasticity in high activity

The rate of internalization of $\mathrm{GABA}_{\mathrm{A}}$ receptors in both control and HA-treated neurons was compared using an antibody feeding protocol. Both control and HA-treated cultures were incubated with antibody directed against the N-terminal (extracellular domain) of $\mathrm{GABA}_{\mathrm{A}}$ receptor $\gamma 2$ subunit. After surface receptors were labeled, cultures were incubated at $37^{\circ} \mathrm{C}$, fixed at multiple time points, and fluorescently tagged with secondary antibodies to observe remaining surface receptors. The receptors disappeared from the surface of control neurons (Fig. 9A, left column) more quickly than from the surface of HA-treated neurons (Fig. 9A, right column). In control neurons, measured fluorescent area dropped sharply after 5 and $10 \mathrm{~min}$ of incubation, whereas HA-treated neurons showed a much slower decline. The rate of internalization of labeled receptors was determined by a single phase decay fit of the fluorescence ratio data by the equation: $Y=Y_{0} e^{(-K \times \text { time })}$, where $Y_{0}$ is the $\mathrm{GABA}_{\mathrm{A}}$ receptor fluorescence ratio at time 0 and $K$ represents the rate constant of $\mathrm{GABA}_{\mathrm{A}}$ receptor internalization in minutes ${ }^{-1}$. The rate constant from the best fit of the data from $24 \mathrm{HA}$-treated neurons ( $0.021 \pm$ $0.002 \mathrm{~min}^{-1}$ ) at each time point was significantly less than that from control neurons $\left(0.10 \pm 0.013 \mathrm{~min}^{-1}, n=23, p<0.005\right)$. The rate constant can be used to describe the time required for a $50 \%$ decrease in the initial fluorescence ratio $Y_{0}$ by division into $\ln 2$, which gives a value $(\ln 2 / K)$ for the half-life $\left(\tau_{1 / 2}\right)$. The half-life of surface $\mathrm{GABA}_{\mathrm{A}}$ receptors in HA-treated neurons was $33.0 \mathrm{~min}$, compared with $6.9 \mathrm{~min}$ in control neurons (Fig. 9B). Thus, the rate at which $\mathrm{GABA}_{\mathrm{A}}$ receptors were internalized was significantly slower in the HA-treated neurons, resulting in the maintenance of a larger population of $\mathrm{GABA}_{\mathrm{A}}$ receptors at the surface compared with control neurons.

\section{Discussion}

This study demonstrated the following. (1) HA treatment through chronic depolarization only transiently increased the firing rate of hippocampal neurons. (2) HA-treated neurons had a 
A

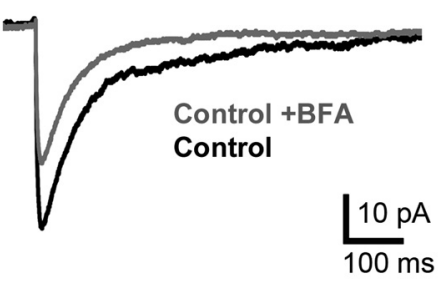

B
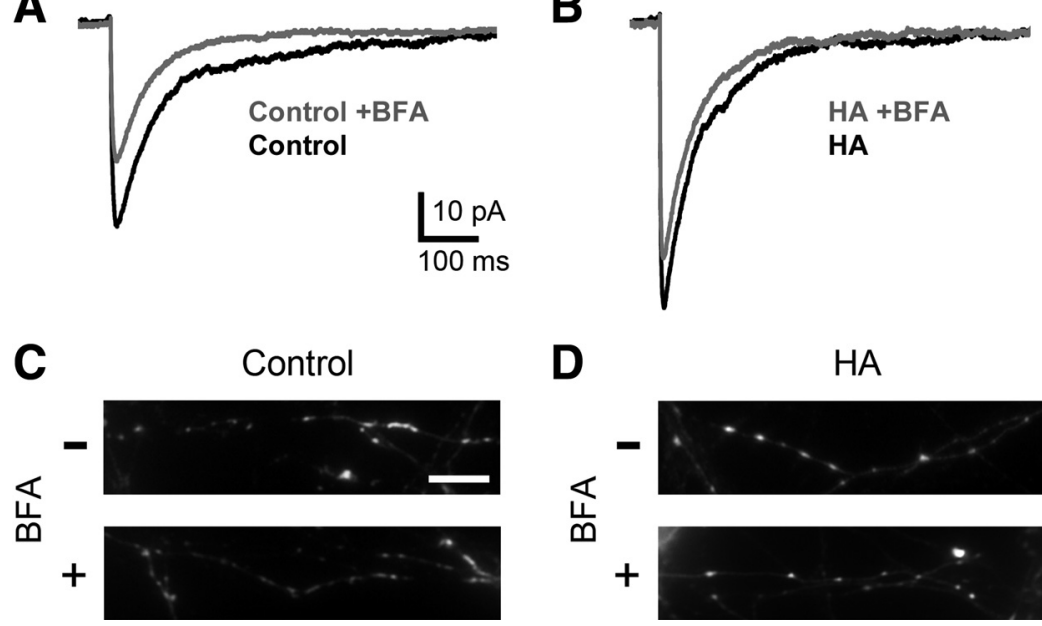

D

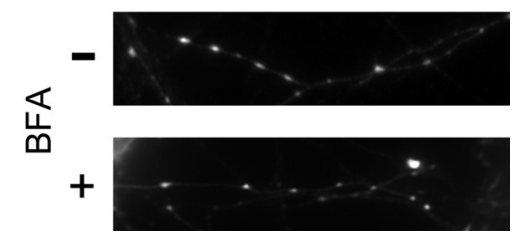

Figure 8. High activity attenuated the decrease of synaptic strength after brefeldin A treatment. $A$, Averaged trace from a representative neuron after $90 \mathrm{~min}$ of brefeldin $\mathrm{A}$ (BFA) treatment superimposed on an average trace from a representative untreated neuron. The mean of median amplitudes for brefeldin A-treated neurons was smaller than untreated neurons. $\boldsymbol{B}$, Average trace from a representative HA-treated neuron after $90 \mathrm{~min}$ of brefeldin $A$ treatment superimposed on an average trace from a representative $\mathrm{HA}$-treated neuron that was not incubated with brefeldin $\mathrm{A}$. The mean of median amplitudes for HA-treated neurons was smaller in those treated with brefeldin A.C, $\gamma 2$ subunit-containing GABAR clusters in dendrites from untreated and brefeldin A-treated neurons. $\gamma 2$ clusters in neurons were smaller after $90 \mathrm{~min}$ of brefeldin A treatment. $\boldsymbol{D}, \gamma 2$ subunit-containing GABAR clusters in dendrites from HA-treated neurons under untreated and brefeldin A-treated conditions. In HA-treated neurons the brefeldin A treatment did not result in a decrease in cluster size. Scale bar, $10 \mu \mathrm{m}$.

muted response to acute depolarization compared with control neurons, thus displaying a homeostatic regulation of excitability. Furthermore, inhibitory synaptic strength increased after HA through coordinated modifications of presynaptic and postsynaptic elements, and this increase was necessary for neuronal firing rate stability. (3) HA decreased the internalization rate of $\mathrm{GABA}_{\mathrm{A}}$ receptors, resulting in their accumulation on the surface membrane, and (4) synaptic strength increased when these receptors were confined to synapses in coordination with presynaptic modifications. These findings support the theory of homeostatic plasticity such that as neuronal excitatory activity increased, inhibitory synapse strength was scaled up to balance the overall firing rate of the neuron.

It is known that scaling of excitatory synaptic strength occurs in response to chronic changes in neuronal activity according to the hypothesis that neurons maintain a stable firing rate through mechanisms of homeostatic plasticity (Turrigiano, 1999). Furthermore, it has been shown that neurons homeostatically scale synaptic strength in response to their own firing rate (Ibata et al., 2008). A stable firing rate is the result of a balance between the natural fluctuations of inhibition and excitation in neural circuits. As previous studies have reported changes in synaptic strength occurring at both inhibitory and excitatory synapses in response to long-term depolarization (Leslie et al., 2001; Peng et al., 2010), we examined whether increased inhibitory synaptic strength corresponded to the homeostatic regulation of the firing rate in hippocampal cultures.

In hippocampal neurons, the stabilization of firing rate after HA demonstrated reduced excitability in the face of acute depolarization. Similar homeostatic stabilization of firing rate after HA induced by chronic bicuculline application was initially demonstrated in cortical neurons (Turrigiano et al., 1998). However, in addition to a return to baseline firing rates, the current study found that this is accompanied by a diminished response to depolarizing high potassium challenge. This altered sensitivity to chang- ing excitability indicates compensatory homeostatic processes occur in hippocampal neurons. As previously hypothesized, these homeostatic mechanisms allow neurons to maintain stable firing rates in the face of perturbations in activity that accompany, for example, developmental changes or Hebbian plasticity (Davis and Bezprozvanny, 2001; Turrigiano and Nelson, 2004; Nelson and Turrigiano, 2008).

Accompanying the observation of firing rate stabilization during HA was an increased accumulation of postsynaptic $\mathrm{GABA}_{\mathrm{A}}$ receptors at the surface membrane and the subsequent incorporation of those receptors into synapses. Three lines of evidence suggested that this initial increase in postsynaptic $\mathrm{GABA}_{\mathrm{A}}$ receptors during $\mathrm{HA}$ was in part due to a diminished internalization rate. First, the increase in $\mathrm{GABA}_{\mathrm{A}}$ receptor surface expression after HA treatment was not accompanied by an increase in the total expression of $\mathrm{GABA}_{\mathrm{A}}$ receptors, suggesting that the accumulation of receptors at the surface was due to changes in trafficking of $\mathrm{GABA}_{\mathrm{A}}$ receptors and not to an increase in receptor transcription or synthesis. Second, when forward trafficking of new receptors from the ER was blocked, the decrease in MIPSC amplitude was smaller in the HA-treated neurons compared with control neurons, suggesting that a larger fraction of receptors remained at synapses during the brefeldin A treatment period in HA-treated neurons. The explanation that a greater fraction of receptors were confined to synapses in HA-treated neurons is also consistent with immunocytochemistry observations. A smaller brefeldin A-induced reduction of $\gamma 2$ subunit cluster size was found in HA-treated neurons than in control neurons. Finally, the surface dwell time of $\mathrm{GABA}_{\mathrm{A}}$ receptors was longer in HA-treated neurons than in control neurons.

Mechanisms of receptor accumulation during long term changes in activity have been described at both glutamatergic synapses (O'Brien et al., 1998; Ehlers, 2003) and GABAergic synapses (Saliba et al., 2007). In addition to receptor internalization, there are other mechanisms of $\mathrm{GABA}_{\mathrm{A}}$ receptor trafficking that could be altered during $\mathrm{HA}$ to result in receptor accumulation at synapses. It is possible that homeostatic plasticity results in receptor internalization rate reaching a new equilibrium after a period of chronic HA. It would be important to understand how other mechanisms of receptor trafficking scale in response to this altered condition. Synaptic activity has been found to regulate the diffusion of both AMPA receptors (Ehlers et al., 2007) and $\mathrm{GABA}_{\mathrm{A}}$ receptors (Bannai et al., 2009) between synaptic and extrasynaptic domains. Recent work has described activity-dependent alterations in $\mathrm{GABA}_{\mathrm{A}}$ receptor diffusion dynamics and the stabilization of $\mathrm{GABA}_{\mathrm{A}}$ receptors at synapses by scaffolding molecules such as gephyrin (Dumoulin et al., 2009; Tyagarajan and Fritschy, 2010). However, further investigation is needed to better understand how these mechanisms might regulate homeostatic plasticity of synaptic strength after chronic changes in activity.

Changes in postsynaptic $\mathrm{GABA}_{\mathrm{A}}$ receptor expression were accompanied by corresponding changes in the presynaptic marker GAD-65 as well (Fig. 7). Our results identify an initial increase in the number of postsynaptic receptors found at the synapse, fol- 
lowed by a slower increase in the size of presynaptic GAD-65 puncta. Presynaptic changes in transmitter release or uptake can affect the transmission of signaling across the synapse. Together, the data are consistent with the conclusion that a homeostatic response to chronic changes in neuronal activity occurs at inhibitory GABAergic synapses through coordinated presynaptic and postsynaptic changes that result in the scaling of synaptic strength.

Changes in MIPSC amplitude have been used previously as a measure of activitydependent scaling of inhibitory synaptic strength (Hartman et al., 2006; Swanwick et al., 2006a), and presynaptic changes in neurotransmitter release have been suggested as a mechanism for decreasing mIPSC amplitude and frequency after chronic activity blockade (Hartman et al., 2006). However, chronic activity blockade has been shown to reduce mIPSC amplitude but not frequency in cultures that have developed mature synaptic connections (Swanwick et al., 2006a). The current study would suggest that reduced inhibitory synaptic strength likely results from accelerated internalization of receptors. Previous studies have shown that decreased activity by TTX-blockade and L-type voltage-gated calcium channels both lead to decreased surface expression of $\mathrm{GABA}_{\mathrm{A}}$ receptor subunit $\beta 3$ (Saliba et al., 2007, 2009).

We found that mIPSC amplitude was larger after $12 \mathrm{~h}$ of HA treatment (Fig. 4). Furthermore, larger mIPSC amplitudes were observed only after the change in synaptic $\mathrm{GABA}_{\mathrm{A}}$ receptor clusters were seen at $6 \mathrm{~h}$, suggesting surface expression of postsynaptic $\mathrm{GABA}_{\mathrm{A}}$ receptors increases before these receptors are incorporated into functional synapses. In addition, the size of GAD- 65 puncta increases at $24 \mathrm{~h}$ of HA, earlier than the increase in mIPSC frequency found at $48 \mathrm{~h}$ of HA treatment. Altered GAD-65 labeling suggests that presynaptic changes have occurred at synapses, but these changes resulting in altered GAD-65 expression are not sufficient to drive increased probability of release. No change was found in the number of synaptic clusters, presynaptic puncta, or in the number of colocalized clusters. Therefore, the increase in probability of release that leads to an increase in the frequency of mIPSCs was not likely due to an increase in the number of synapses or an increase in the number of vesicle release sites. However, higher resolution imaging may be necessary to eliminate the possibility of an increase in the number of multiple receptor clusters colocalizing within larger presynaptic puncta.

Our data suggest that changes in synaptic strength arise from multiple homeostatic mechanisms occurring at different rates. The time scale of homeostatic change observed is similar to observations made at glutamatergic synapses under activity blockade (Turrigiano et al., 1998). This similarity confirms that multiple mechanisms regulating homeostatic plasticity are globally scaling synaptic strength in coordination, thus preserving stable levels of excitability and the firing rate. We have shown here that the in- crease in GABAergic transmission at the synapse after HA is a necessary component to homeostatic plasticity. Application of a low concentration of bicuculline reduced GABAergic synaptic strength in HA-treated neurons to the level of control neurons. When this concentration was applied to spontaneously firing HA-treated neurons, the frequency of action potentials increased significantly, demonstrating that the increase in GABAergic synaptic strength was necessary to the maintenance of the homeostatically scaled firing rate.

At glutamatergic synapses, the expression of AMPA receptors have been found to homeostatically scale in response to changes in activity (O'Brien et al., 1998; Wierenga et al., 2005). Furthermore, homeostatic scaling of synaptic strength has been associated with similarly coordinated presynaptic and postsynaptic responses at excitatory synapses (Wierenga et al., 2006). This coordinated process of synaptic modification could occur by retrograde signaling, which has been recently described for glutamatergic synapses through BDNF-TrkB signaling (Jakawich et al., 2010). BDNF modulates activitydependent scaling of GABAergic synaptic strength after chronic activity blockade as well (Swanwick et al., 2006a), and has been identified as a potential messenger of retrograde signaling at 
GABAergic synapses after increases in activity (Peng et al., 2010).

Studies investigating the time course of activity-dependent changes at excitatory synapses have also reported different temporal changes under different neuronal culture preparations (Turrigiano et al., 1998; Ibata et al., 2008). The role of growth factors from glial cells in culture is important to neuronal development in vitro, and glial cytokine TNF- $\alpha$ has been shown to be important in synaptic scaling during both activity blockade in culture (Stellwagen and Malenka, 2006) and during development in vivo (Kaneko et al., 2008). There is expanding knowledge of how factors like TNF- $\alpha$ and BDNF shape mechanisms of homeostatic plasticity in response to changes in activity. Differences in glial interaction during neuronal development could alter the processes that regulate homeostatic scaling at synapses. The recent report from Peng et al. describes changes in both amplitude and frequency of mIPSCs as early as $4 \mathrm{~h}$ into a HA treatment. Importantly, our finding that frequency of mIPSCs increased on a different time scale than mIPSC amplitude suggests that the overall increase in synaptic strength may not arise from a single mechanism or locus of change.

Furthermore, mIPSC decay was observed to change in HAtreated neurons, suggesting that the subunit composition of receptors at inhibitory synapses could also be altered with $48 \mathrm{~h}$ of HA treatment. Deactivation and desensitization properties of receptors on the postsynaptic membrane shape mIPSC kinetics (Jones and Westbrook, 1995; Haas and Macdonald, 1999; Bianchi et al., 2007). The number of postsynaptic receptors clustering at a synapse can determine synaptic strength, and the subunit composition of these receptors can determine whether synapses are targeted to synapses (Essrich et al., 1998). $\mathrm{GABA}_{\mathrm{A}}$ receptor populations with varying subunit composition can have different trafficking characteristics, and differential expression of these receptor types during HA treatment may determine the changing properties of mIPSC kinetics seen as inhibitory synaptic strength increases. Subunit composition can also affect tonic inhibition through the distribution of extrasynaptic $\mathrm{GABA}_{\mathrm{A}}$ receptors. There is evidence that an increase in extrasynaptic $\delta$ subunitcontaining $\mathrm{GABA}_{\mathrm{A}}$ receptors corresponds to decreased excitability during the estrous cycle in rats (Maguire et al., 2005). In chronic epilepsy, a condition where action potential firing is not stably maintained by neuronal circuits, tonic inhibition is preserved while the expression of $\delta$ subunit-containing $\mathrm{GABA}_{\mathrm{A}}$ receptors is decreased (Zhang et al., 2007; Rajasekaran et al., 2010). Future work will be needed to determine the relationship between the scaling of fast, synaptic GABAergic synaptic transmission during $\mathrm{HA}$ and the scaling of tonic inhibition in neurons. It also remains to be seen whether the changes in GABAergic synaptic strength after chronic high activity are similarly scaled over time in an in vivo treatment. Kainate injection in rats was shown to induce increases in mIPSC amplitude and frequency as well BDNF protein level (Peng et al., 2010). Similar to our findings, this suggests both postsynaptic and presynaptic mechanisms regulate in vivo homeostatic scaling of GABAergic synapses in response to increased neuronal firing. A better understanding of how the trafficking of $\mathrm{GABA}_{\mathrm{A}}$ receptors is altered with elevated activity in the intact brain is needed to understand the limits of homeostatic plasticity and its role in regulating neuronal activity in the healthy brain.

These data suggest that the temporal regulation of multiple mechanisms continues to occur at inhibitory synapses during HA, even after synaptic strength has ceased further increases and the firing rate has stabilized. Mechanisms beyond receptor accu- mulation are necessary for inhibitory synaptic scaling, as the initial increase in postsynaptic surface membrane receptors alone did not appear sufficient to increase inhibitory synaptic strength during HA. Our results predict that mechanisms of receptor trafficking lead to the accumulation of receptors targeted to synapses where corresponding presynaptic feedback is necessary for the homeostatic scaling of inhibitory synaptic strength and the regulation of the neuronal firing rate.

\section{References}

Bannai H, Lévi S, Schweizer C, Inoue T, Launey T, Racine V, Sibarita JB, Mikoshiba K, Triller A (2009) Activity-dependent tuning of inhibitory neurotransmission based on GABAAR diffusion dynamics. Neuron 62:670-682.

Benson DL, Watkins FH, Steward O, Banker G (1994) Characterization of GABAergic neurons in hippocampal cell cultures. J Neurocytol 23:279-295.

Bianchi MT, Macdonald RL (2001) Agonist Trapping by GABAA Receptor Channels. J Neurosci 21:9083-9091.

Bianchi MT, Botzolakis EJ, Haas KF, Fisher JL, Macdonald RL (2007) Microscopic kinetic determinants of macroscopic currents: insights from coupling and uncoupling of GABAA receptor desensitization and deactivation. J Physiol 584:769-787.

Christie SB, Miralles CP, De Blas AL (2002) GABAergic innervation organizes synaptic and extrasynaptic GABAA receptor clustering in cultured hippocampal neurons. J Neurosci 22:684-697.

Davis GW, Bezprozvanny I (2001) Maintaining the stability of neural function: a homeostatic hypothesis. Annu Rev Physiol 63:847-869.

Dumoulin A, Triller A, Kneussel M (2009) Cellular transport and membrane dynamics of the glycine receptor. Front Mol Neurosci 2:28.

Ehlers MD (2003) Activity level controls postsynaptic composition and signaling via the ubiquitin-proteasome system. Nat Neurosci 6:231-242.

Ehlers MD, Heine M, Groc L, Lee MC, Choquet D (2007) Diffusional trapping of GluR1 AMPA receptors by input-specific synaptic activity. Neuron 54:447-460.

Essrich C, Lorez M, Benson JA, Fritschy JM, Lüscher B (1998) Postsynaptic clustering of major GABAA receptor subtypes requires the gamma 2 subunit and gephyrin. Nat Neurosci 1:563-571.

Frerking M, Borges S, Wilson M (1995) Variation in GABA mini amplitude is the consequence of variation in transmitter concentration. Neuron 15:885-895.

Fujiwara T, Oda K, Yokota S, Takatsuki A, Ikehara Y (1988) Brefeldin A causes disassembly of the Golgi complex and accumulation of secretory proteins in the endoplasmic reticulum. J Biol Chem 263:18545-18552.

Goodkin HP, Joshi S, Mtchedlishvili Z, Brar J, Kapur J (2008) Subunitspecific trafficking of $\mathrm{GABA}(\mathrm{A})$ receptors during status epilepticus. J Neurosci 28:2527-2538.

Goslin K, Asmussen H, Banker G (1998) Rat hippocampal neurons in lowdensity culture. In: Culturing nerve cells (Banker G, Goslin K, eds), pp 339-370. Cambridge, MA: MIT.

Haas KF, Macdonald RL (1999) GABAA receptor subunit gamma2 and delta subtypes confer unique kinetic properties on recombinant GABAA receptor currents in mouse fibroblasts. J Physiol 514:27-45.

Hartman KN, Pal SK, Burrone J, Murthy VN (2006) Activity-dependent regulation of inhibitory synaptic transmission in hippocampal neurons. Nat Neurosci 9:642-649.

Ibata K, Sun Q, Turrigiano GG (2008) Rapid synaptic scaling induced by changes in postsynaptic firing. Neuron 57:819-826.

Jakawich SK, Nasser HB, Strong MJ, McCartney AJ, Perez AS, Rakesh N, Carruthers CJ, Sutton MA (2010) Local presynaptic activity gates homeostatic changes in presynaptic function driven by dendritic BDNF synthesis. Neuron 68:1143-1158.

Jones MV, Westbrook GL (1995) Desensitized states prolong GABAA channel responses to brief agonist pulses. Neuron 15:181-191.

Joshi S, Kapur J (2009) Slow intracellular accumulation of GABA(A) receptor delta subunit is modulated by brain-derived neurotrophic factor. Neuroscience 164:507-519.

Joshi S, Sun C, Kapur J (2011) A mouse monoclonal antibody against the gamma2 subunit of GABA-A receptors. Hybridoma, in press.

Kaneko M, Stellwagen D, Malenka RC, Stryker MP (2008) Tumor necrosis factor-alpha mediates one component of competitive, experiencedependent plasticity in developing visual cortex. Neuron 58:673-680. 
Leslie KR, Nelson SB, Turrigiano GG (2001) Postsynaptic depolarization scales quantal amplitude in cortical pyramidal neurons. J Neurosci 21:RC170(1-6)

Lissin DV, Gomperts SN, Carroll RC, Christine CW, Kalman D, Kitamura M, Hardy S, Nicoll RA, Malenka RC, von Zastrow M (1998) Activity differentially regulates the surface expression of synaptic AMPA and NMDA glutamate receptors. Proc Natl Acad Sci U S A 95:7097-7102.

Lo WY, Botzolakis EJ, Tang X, Macdonald RL (2008) A conserved Cys-loop receptor aspartate residue in the $\mathrm{M} 3-\mathrm{M} 4$ cytoplasmic loop is required for GABAA receptor assembly. J Biol Chem 283:29740-29752.

Maconochie DJ, Zempel JM, Steinbach JH (1994) How quickly can GABAA receptors open? Neuron 12:61-71.

Maguire JL, Stell BM, Rafizadeh M, Mody I (2005) Ovarian cycle-linked changes in $\operatorname{GABA}(\mathrm{A})$ receptors mediating tonic inhibition alter seizure susceptibility and anxiety. Nat Neurosci 8:797-804.

Mangan PS, Kapur J (2004) Factors underlying bursting behavior in a network of cultured hippocampal neurons exposed to zero magnesium. J Neurophysiol 91:946-957.

Mangan PS, Sun C, Carpenter M, Goodkin HP, Sieghart W, Kapur J (2005) Cultured hippocampal pyramidal neurons express two kinds of GABAA receptors. Mol Pharmacol 67:775-788.

Marder E, Goaillard JM (2006) Variability, compensation and homeostasis in neuron and network function. Nat Rev Neurosci 7:563-574.

Mi R, Tang X, Sutter R, Xu D, Worley P, O’Brien RJ (2002) Differing mechanisms for glutamate receptor aggregation on dendritic spines and shafts in cultured hippocampal neurons. J Neurosci 22:7606-7616.

Nelson SB, Turrigiano GG (2008) Strength through diversity. Neuron 60:477-482.

Nusser Z, Cull-Candy S, Farrant M (1997) Differences in synaptic GABA(A) receptor number underlie variation in GABA mini amplitude. Neuron 19:697-709.

Nusser Z, Hájos N, Somogyi P, Mody I (1998) Increased number of synaptic $\mathrm{GABA}(\mathrm{A})$ receptors underlies potentiation at hippocampal inhibitory synapses. Nature 395:172-177.

O’Brien RJ, Kamboj S, Ehlers MD, Rosen KR, Fischbach GD, Huganir RL (1998) Activity-dependent modulation of synaptic AMPA receptor accumulation. Neuron 21:1067-1078.

Peng YR, Zeng SY, Song HL, Li MY, Yamada MK, Yu X (2010) Postsynaptic spiking homeostatically induces cell-autonomous regulation of inhibitory inputs via retrograde signaling. J Neurosci 30:16220-16231.

Rajasekaran K, Joshi S, Sun C, Mtchedlishvilli Z, Kapur J (2010) Receptors with low affinity for neurosteroids and GABA contribute to tonic inhibition of granule cells in epileptic animals. Neurobiol Dis 40:490-501.

Rao A, Craig AM (1997) Activity regulates the synaptic localization of the NMDA receptor in hippocampal neurons. Neuron 19:801-812.

Rao A, Cha EM, Craig AM (2000) Mismatched appositions of presynaptic and postsynaptic components in isolated hippocampal neurons. J Neurosci 20:8344-8353.

Saliba RS, Michels G, Jacob TC, Pangalos MN, Moss SJ (2007) Activitydependent ubiquitination of GABA(A) receptors regulates their accumulation at synaptic sites. J Neurosci 27:13341-13351.

Saliba RS, Gu Z, Yan Z, Moss SJ (2009) Blocking L-type voltage-gated $\mathrm{Ca}^{2+}$ channels with dihydropyridines reduces gamma-aminobutyric acid type A receptor expression and synaptic inhibition. J Biol Chem 284:32544-32550.

Stellwagen D, Malenka RC (2006) Synaptic scaling mediated by glial TNFalpha. Nature 440:1054-1059.

Swanwick CC, Murthy NR, Kapur J (2006a) Activity-dependent scaling of GABAergic synapse strength is regulated by brain-derived neurotrophic factor. Mol Cell Neurosci 31:481-492.

Swanwick CC, Murthy NR, Mtchedlishvili Z, Sieghart W, Kapur J (2006b) Development of gamma-aminobutyric acidergic synapses in cultured hippocampal neurons. J Comp Neurol 495:497-510.

Turrigiano GG (1999) Homeostatic plasticity in neuronal networks: the more things change, the more they stay the same. Trends Neurosci 22: 221-227.

Turrigiano GG, Nelson SB (2004) Homeostatic plasticity in the developing nervous system. Nat Rev Neurosci 5:97-107.

Turrigiano GG, Leslie KR, Desai NS, Rutherford LC, Nelson SB (1998) Activity-dependent scaling of quantal amplitude in neocortical neurons. Nature 391:892-896.

Tyagarajan SK, Fritschy JM (2010) GABA(A) receptors, gephyrin and homeostatic synaptic plasticity. J Physiol 588:101-106.

Wierenga CJ, Ibata K, Turrigiano GG (2005) Postsynaptic expression of homeostatic plasticity at neocortical synapses. J Neurosci 25:2895-2905.

Wierenga CJ, Walsh MF, Turrigiano GG (2006) Temporal regulation of the expression locus of homeostatic plasticity. J Neurophysiol 96:2127-2133.

Zhang N, Wei W, Mody I, Houser CR (2007) Altered localization of GABA(A) receptor subunits on dentate granule cell dendrites influences tonic and phasic inhibition in a mouse model of epilepsy. J Neurosci $27: 7520-7531$. 